\title{
Gene signatures of genomic instability as prognostic tools for breast cancer
}

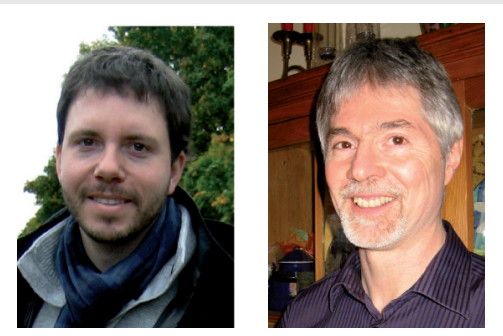

“...multigene signatures have emerged as an important molecular tool that can provide useful prognostic and predictive information..."

Laurent Sansregret' \& Alain Nepveu ${ }^{\dagger 2,3}$

'Cancer Research UK London Research Institute, Clare Hall Laboratories, South Mimms, Hertfordshire, EN6 3LD, UK

2Rosalind \& Morris Goodman Cancer Research Centre, McGill University, Montreal, Quebec, Canada ${ }^{3}$ Departments of Biochemistry, Oncology \& Medicine, McGill University, Montreal, Quebec, H3A 1A3 Canada †Author for correspondence: Tel.: +1 5143985839 = Fax: +1 5143986769 = alain.nepveu@mcgill.ca

Breast cancer remains a challenge to treat, in part owing to the heterogeneity of the disease. Breast cancers vary greatly in terms of prognosis and in the way they respond to targeted or systemic therapies [1,2]. Unfortunately, chemotherapy is associated with short- and long-term toxicities [3]. Therefore, it is crucial to identify patients who can be spared from unnecessary adjuvant therapy and those who must be treated with aggressive therapies. In the last decade, multigene signatures have emerged as an important molecular tool that can provide useful prognostic and predictive information in addition to classical clinicopathological criteria (reviewed in $[4,5]$ ). The first expression profiling studies in breast cancers have succeeded in defining molecular subtypes with distinct prognosis: luminal epithelial/estrogen receptor-positive $\left(\mathrm{ER}^{+}\right)$(luminal A, luminal B), HER2+, basallike and normal-like [6-8]. Subsequent expression profiling studies have been performed with the aim of defining a relatively small set of genes whose expression at the mRNA level would help identify breast cancer patients who are at risk of recurrence (reviewed in [4,5,9]). Most gene signatures include a large component of genes that are involved in cell proliferation [10-16]. Interestingly, these signatures appear to track similar biological signatures as the major subtypes [17-19]. Other gene signatures have focused on distinct biological processes such as wound response [20,21], invasiveness [22], 'stemness' [23-25] or genetic instability [26-28].

Genomic instability, as defined by the stemline scatter index [29], was analyzed in 890 primary breast carcinoma patients and was shown to be a useful prognostic indicator, independent of established clinical factors [26]. Comparing genomic instability and expression profiling data, Habermann and coworkers defined a 12-gene genomic instability signature that was shown to predict metastasis-free survival in three independent breast cancer datasets, and represented a prognostic marker that is independent of traditional clinicopathologic factors [27]. Interestingly, a firm association was established between genomic instability and breast cancer subtypes [27].

"In a study by Carter and coworkers, a signature of chromosomal instability was established from specific genes whose expression was consistently correlated with chromosomal aberrations."

In a study by Carter and coworkers, a signature of chromosomal instability was established from specific genes whose expression was consistently correlated with chromosomal aberrations [28]. The rationale was to use gene expression data to infer chromosomal imbalance at sub-band resolution. Therefore, the authors did not attempt to identify genes that cause chromosomal instability (CIN), but instead derived lists of 70 or 25 genes, CIN70 and CIN25, respectively, whose differential expression was symptomatic of chromosomal instability. The CIN25 signature was shown to be a significant predictor of clinical outcome in 12 out of 18 tumor datasets, including four breast tumor databases [28]. Another prognostic signature, termed complexity index in sarcoma (CINSARC), was established by combining genes that were differentially expressed in 183 sarcomas when tumors were classified using either comparative genomic

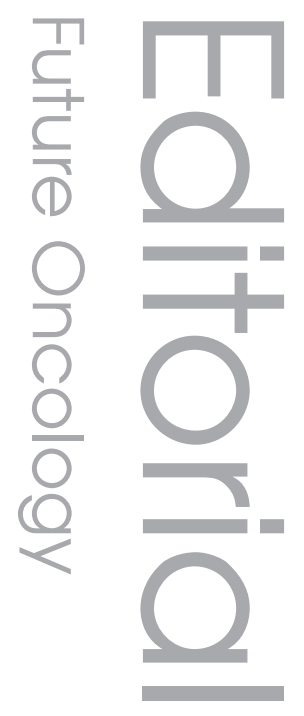

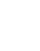

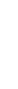


hybridization array analysis, histological grade or the CIN70 signature [30]. All these genes were submitted to gene ontology analysis to keep 67 genes that belonged to overrepresented pathways for comparative genomic hybridization or histological grade. A training/validation methodology was then used to demonstrate that the CINSARC signature was able to predict outcome in two breast cancer databases [12,13].

In a recent study on the mechanism by which the CUX1 homeodomain protein promotes genetic instability, we have uncovered a gene signature that can predict clinical outcome among $\mathrm{ER}^{+} /$lymph node-negative $\left(\mathrm{LN}^{-}\right)$breast cancer patients [31]. CUX1 is a transcription factor that is overexpressed in various human cancers [32-34], particularly in breast cancers [35,36]. In situ hybridization performed on multiple tissue core arrays showed increased $C U X 1$ expression within highgrade, but not low-grade, breast carcinomas [36]. Immunohistochemical analysis on a separate series of breast and pancreatic cancer tissues also demonstrated that CUX1 protein expression was increased in the high histological-grade tumors compared with low-grade tumors [36,37]. Moreover, among patients with grade 3 breast tumors, CUX1 mRNA expression inversely correlated with relapse-free and overall survival [36]. In tissue culture systems, CUX1 was shown to accelerate entry into $S$ phase during cell-cycle progression, and to promote cell motility and invasion [36-39]. In mouse models, expression of CUX1 in the mammary gland of transgenic mice causes the development of mammary tumors of various histological types that exhibit extensive genetic instability $[31,40]$. Recent work led to the identification and validation of CUX1 transcriptional targets that promote DNA replication, prevent multipolar division and enable the survival of cells that contain more than two centrosomes [31]. These cells evolved to become aneuploid and tumorigenic [31]. CUX1 targets a defined 29-gene expression signature termed CUX1 signature (C1S), which was then applied to 12 previously published gene expression datasets derived from whole-tumor breast tissues [31]. The breast cancer molecular subtypes were not distributed equally between the 'low'- and 'high'-expression groups as classified by the C1S [31,41]. Those subtypes with increased genetic instability and a poorer outcome, namely HER $2^{+}$and basal-like [27,42], were over-represented in the $\mathrm{C} 1 \mathrm{~S}$ high-expression group, while the proportion in the good outcomeenriched luminal A subtype was much reduced (see Figure 4 in [31]). However, the signature identified subgroups of $\mathrm{ER}^{+} / \mathrm{LN}^{-}$patients with poorer clinical outcome [31]. Furthermore, when this cohort was separated into subtypes, the signature was able to identify poor outcome among the luminal A group, which is the subtype considered to be at the lowest risk [31]. Importantly, multivariate COX regression analysis demonstrated that the C1S signature is a significant predictor of outcome that is independent of grade, $\mathrm{LN}$ and ER status [31].

We contend that gene lists that track down genetic instability have the potential to greatly improve the prognostic value of gene signatures. Indeed, a crucial property associated with tumor progression is the ability of tumor cells to evolve rapidly and generate large repertoires of genetic variants. Most genetic variations are expected to be deleterious; however, if genetic variants reach a high number or are generated at a high enough frequency, rare variants will unavoidably emerge with increased proliferative, invasive and immune-suppressive properties. The capacity of tumor cells to evolve is evidenced in the biological heterogeneity of tumors [43-45], as well as in their genomic heterogeneity [46-49]. Moreover, the fact that metastatic tumor cells display an expression profile and exhibit biological properties that are different from that of the primary tumor has been amply documented in several studies [50-53]. If we accept, as a premise, that primary tumor cells must evolve in order to acquire novel metastatic properties, it follows logically that a gene signature that measures the evolutionary potential of primary tumors will also predict clinical outcome.

\section{"If we accept... that primary tumor cells must evolve in order to acquire novel metastatic properties, it follows logically that a gene signature that measures the evolutionary potential of primary tumors will also predict clinical outcome."}

Interestingly, the CINSARC and C1S signatures have much in common [30,31]. A total of 14 out of the 29 genes in the C1S list are present within CINSARC. Moreover, genes in both signatures are involved in the same biological processes, which can be summarized as gene replication, mitosis checkpoint and centrosome dynamics. The similarities in cellular functions between the C1S and CINSARC signatures are interesting in that they shed light on the underlying mechanisms of genetic instability in cancer cells and confirm the generality of findings made in each of these studies. While tetraploidy 
is observed in only a small minority of breast cancers [54], numerical and structural centrosome aberrations can be detected in a sizeable fraction of cells in breast lesion biopsies [29,55]. Importantly, a clear association was established between centrosome aberrations and genetic instability [55,56]. The mechanistic link between genetic instability and structural abnormalities in centrosomes remains to be defined; however, recent evidence has shed light on the consequences of having extra centrosome numbers [57]. In experimental systems, centrosome amplification was shown to cause the formation of multipolar spindles in mitosis. In normal cells, multipolar divisions follow the formation of multipolar spindles and generate mostly nonviable daughter cells. By contrast, certain cancer cells, notably cells that express the $\mathrm{C} 1 \mathrm{~S}$ signature, are able to engage a robust spindle assembly checkpoint that extends the duration of mitosis until the multiple centrosomes have clustered into two poles, thereby allowing bipolar mitosis and cell survival $[31,58]$. Yet, transient multipolar spindles in these cells are associated with increased occurrence of merotely, which, if not corrected, causes chromosome missegregation [57,59]. Other genes in the
C1S signatures are directly involved in centrosome dynamics and may contribute to chromosomal instability by mechanisms that remain to be defined [31]. Overall, the information obtained from multiple studies suggest that protection from mitotic catastrophe together with frequent chromosome missegregation events contribute to the generation of large populations of genetic variants from which tumorigenic cells emerge with metastatic properties. These findings not only increase our understanding of the molecular mechanisms underlying genomic instability, they also provide gene signatures that will serve as a useful prognostic tool for lymph node-negative estrogen receptor-positive breast cancers.

\section{Financial \& competing interests disclosure \\ The authors have no relevant affiliations or financial involvement with any organization or entity with a financial interest in or financial conflict with the sub- ject matter or materials discussed in the manuscript. This includes employment, consultancies, honoraria, stock ownership or options, expert testimony, grants or patents received or pending, or royalties. \\ No writing assistance was utilized in the production of this manuscript.}

\section{Bibliography}

1. Bevers TB, Anderson BO, Bonaccio E et al:: NCCN clinical practice guidelines in oncology: breast cancer screening and diagnosis. J. Natl Compr. Canc. Netw. 7, 1060-1096 (2009).

2. Carlson RW, Allred DC, Anderson BO et al.: Breast cancer. Clinical practice guidelines in oncology. J. Natl Compr. Canc. Netw. 7, 122-192 (2009).

3. Azim HA Jr, de Azambuja E, Colozza M, Bines J, Piccart MJ: Long-term toxic effects of adjuvant chemotherapy in breast cancer. Ann. Oncol. DOI: 10.1093/annonc/mdq683 (2011) (Epub ahead of print).

4. Oakman C, Santarpia L, Di Leo A: Breast cancer assessment tools and optimizing adjuvant therapy. Nat. Rev. Clin. Oncol. 7 , 725-732 (2010).

5. Subramanian J, Simon R: What should physicians look for in evaluating prognostic gene-expression signatures? Nat. Rev. Clin. Oncol. 7, 327-334 (2010).

6. Perou CM, Sorlie T, Eisen MB et al:: Molecular portraits of human breast tumours. Nature 406, 747-752 (2000).

7. Sorlie T, Perou CM, Tibshirani R et al.: Gene expression patterns of breast carcinomas distinguish tumor subclasses with clinical implications. Proc. Natl Acad. Sci. USA 98, 10869-10874 (2001).
8. Sorlie T, Tibshirani R, Parker J et al.: Repeated observation of breast tumor subtypes in independent gene expression data sets. Proc. Natl Acad. Sci. USA 100, 8418-8423 (2003).

9. Ellsworth RE, Decewicz DJ, Shriver CD, Ellsworth DL: Breast cancer in the personal genomics era. Curr. Genomics 11, 146-161 (2010).

10. Paik S, Shak S, Tang G et al:: A multigene assay to predict recurrence of tamoxifen-treated, node-negative breast cancer. N. Engl. J. Med. 351, 2817-2826 (2004).

11. Paik S, Tang G, Shak S et al:: Gene expression and benefit of chemotherapy in women with node-negative, estrogen receptor-positive breast cancer. J. Clin. Oncol. 24, 3726-3734 (2006).

12. Van't Veer LJ, Dai H, van de Vijver MJ et al:: Gene expression profiling predicts clinical outcome of breast cancer. Nature 415, 530-536 (2002).

13. van de Vijver MJ, He YD, van't Veer LJ et al.: A gene-expression signature as a predictor of survival in breast cancer. N. Engl. J. Med. 347, 1999-2009 (2002).

14. Sotiriou C, Wirapati P, Loi S et al:: Gene expression profiling in breast cancer: understanding the molecular basis of histologic grade to improve prognosis. J. Natl Cancer Inst. 98, 262-272 (2006).

15. Loi S, Haibe-Kains B, Desmedt C et al.: Definition of clinically distinct molecular subtypes in estrogen receptor-positive breast carcinomas through genomic grade. J. Clin. Oncol. 25, 1239-1246 (2007).

16. Wang Y, Klijn JG, Zhang Y et al.: Geneexpression profiles to predict distant metastasis of lymph-node-negative primary breast cancer. Lancet 365, 671-679 (2005).

17. Cardoso F, Van't Veer L, Rutgers E, Loi S, Mook S, Piccart-Gebhart MJ: Clinical application of the 70 -gene profile: the MINDACT trial. J. Clin. Oncol. 26, 729-735 (2008).

18. Zujewski JA, Kamin L: Trial assessing individualized options for treatment for breast cancer: the TAILORx trial. Future Oncol. 4, 603-610 (2008).

19. Fan C, Oh DS, Wessels L et al:: Concordance among gene-expression-based predictors for breast cancer. N. Engl. J. Med. 355, 560-569 (2006).

20. Chang HY, Sneddon JB, Alizadeh AA et al.: Gene expression signature of fibroblast serum response predicts human cancer progression: similarities between tumors and wounds. PLoS Biol. 2, E7 (2004). 
21. Chang HY, Nuyten DS, Sneddon JB et al:: Robustness, scalability, and integration of a wound-response gene expression signature in predicting breast cancer survival. Proc. Natl Acad. Sci. USA 102, 3738-3743 (2005).

22. Liu R, Wang X, Chen GY et al: : The prognostic role of a gene signature from tumorigenic breast-cancer cells. N. Engl. J. Med. 356, 217-226 (2007).

23. Ben-Porath I, Thomson MW, Carey VJ et al.: An embryonic stem cell-like gene expression signature in poorly differentiated aggressive human tumors. Nat. Genet. 40, 499-507 (2008).

24. Wong DJ, Liu H, Ridky TW, Cassarino D, Segal E, Chang HY: Module map of stem cell genes guides creation of epithelial cancer stem cells. Cell Stem Cell 2, 333-344 (2008).

25. Shats I, Gatza ML, Chang JT et al:: Using a stem cell-based signature to guide therapeutic selection in cancer. Cancer Res. 71(5), 1772-1780 (2010).

26. Kronenwett U, Ploner A, Zetterberg A et al: : Genomic instability and prognosis in breast carcinomas. Cancer Epidemiol. Biomarkers Prev. 15, 1630-1635 (2006).

27. Habermann JK, Doering J, Hautaniemi S et al:: The gene expression signature of genomic instability in breast cancer is an independent predictor of clinical outcome. Int. J. Cancer 124, 1552-1564 (2009).

28. Carter SL, Eklund AC, Kohane IS, Harris LN, Szallasi Z: A signature of chromosomal instability inferred from gene expression profiles predicts clinical outcome in multiple human cancers. Nat. Genet. 38, 1043-1048 (2006).

29. Kronenwett U, Huwendiek S, Ostring C et al.: Improved grading of breast adenocarcinomas based on genomic instability. Cancer Res. 64, 904-909 (2004).

30. Chibon F, Lagarde P, Salas S et al.: Validated prediction of clinical outcome in sarcomas and multiple types of cancer on the basis of a gene expression signature related to genome complexity. Nat. Med. 16, 781-787 (2010).

31. Sansregret L, Vadnais C, Livingstone J et al.: Cut homeobox 1 causes chromosomal instability by promoting bipolar division after cytokinesis failure. Proc. Natl Acad. Sci. USA 108, 1949-1954 (2011).

32. De Vos J, Thykjaer T, Tarte K et al.: Comparison of gene expression profiling between malignant and normal plasma cells with oligonucleotide arrays. Oncogene 21, 6848-6857 (2002).
33. Moon NS, Rong Zeng W, Premdas P, Santaguida M, Berube G, Nepveu A: Expression of N-terminally truncated isoforms of CDP/CUX is increased in human uterine leiomyomas. Int. J. Cancer 100, 429-432 (2002).

34. Ripka S, Neesse A, Riedel J et al.: CUX1: target of Akt signalling and mediator of resistance to apoptosis in pancreatic cancer. Gut 59, 1101-1110 (2010).

35. Goulet B, Watson P, Poirier M et al.: Characterization of a tissue-specific CDP/Cux isoform, p75, activated in breast tumor cells. Cancer Res. 62, 6625-6633 (2002).

36. Michl P, Ramjaun AR, Pardo OE et al:: CUTL1 is a target of TGF $\beta$ signaling that enhances cancer cell motility and invasiveness. Cancer Cell 7, 521-532 (2005).

37. Ripka S, Konig A, Buchholz M et al.: WNT5A - target of CUTL1 and potent modulator of tumor cell migration and invasion in pancreatic cancer. Carcinogenesis 28, 1178-1187 (2007).

38. Aleksic T, Bechtel M, Krndija D et al.: CUTL1 promotes tumor cell migration by decreasing proteasome-mediated Src degradation. Oncogene 26, 5939-5949 (2007).

39. Kedinger V, Sansregret L, Harada R et al.: p110 CUX1 homeodomain protein stimulates cell migration and invasion in part through a regulatory cascade culminating in the repression of E-cadherin and occludin. J. Biol. Chem. 284, 27701-27711 (2009).

40. Cadieux C, Kedinger V, Yao L et al.: Mouse mammary tumor virus p75 and p110 CUX1 transgenic mice develop mammary tumors of various histologic types. Cancer Res. 69, 7188-7197 (2009).

41. Parker JS, Mullins M, Cheang MC et al: Supervised risk predictor of breast cancer based on intrinsic subtypes. J. Clin. Oncol. 27, 1160-1167 (2009).

42. Calza S, Hall P, Auer G et al.: Intrinsic molecular signature of breast cancer in a population-based cohort of 412 patients. Breast Cancer Res. 8, R34 (2006).

43. Hanna W, Nofech-Mozes S, Kahn HJ: Intratumoral heterogeneity of HER2/neu in breast cancer - a rare event. Breast J. 13, 122-129 (2007).

44. Cottu PH, Asselah J, Lae M et al.: Intratumoral heterogeneity of HER $2 /$ neu expression and its consequences for the management of advanced breast cancer. Ann. Oncol. 19, 595-597 (2008).

45. Iliopoulos D, Hirsch HA, Wang G, Struhl K: Inducible formation of breast cancer stem cells and their dynamic equilibrium with non-stem cancer cells via IL6 secretion. Proc. Natl Acad. Sci. USA 108, 1397-1402 (2011).

46. Korkola J, Gray JW: Breast cancer genomes form and function. Curr. Op. Genet. Dev. 20, 4-14 (2010).

47. Shah SP, Morin RD, Khattra J et al.: Mutational evolution in a lobular breast tumour profiled at single nucleotide resolution. Nature 461, 809-813 (2009).

48. Swanton C, Burrell RA, Futreal PA: Breast cancer genome heterogeneity: a challenge to personalised medicine? Breast Cancer Res. 13, 104 (2011).

49. Navin N, Krasnitz A, Rodgers L et al.: Inferring tumor progression from genomic heterogeneity. Genome Res. 20, 68-80 (2010).

50. Khalique L, Ayhan A, Whittaker JC et al.: The clonal evolution of metastases from primary serous epithelial ovarian cancers. Int. J. Cancer 124, 1579-1586 (2009).

51. Torres L, Ribeiro FR, Pandis N, Andersen JA, Heim S, Teixeira MR: Intratumor genomic heterogeneity in breast cancer with clonal divergence between primary carcinomas and lymph node metastases. Breast Cancer Res. Treat. 102, 143-155 (2007).

52. Yachida S, Jones S, Bozic I et al.: Distant metastasis occurs late during the genetic evolution of pancreatic cancer. Nature 467, 1114-1117 (2010).

53. Campbell PJ, Yachida S, Mudie LJ et al: The patterns and dynamics of genomic instability in metastatic pancreatic cancer. Nature 467, 1109-1113 (2010).

54. Storchova Z, Kuffer C: The consequences of tetraploidy and aneuploidy. J. Cell Sci. 121, 3859-3866 (2008).

55. Kronenwett U, Huwendiek S, Castro J, Ried T, Auer G: Characterisation of breast fine-needle aspiration biopsies by centrosome aberrations and genomic instability. Br. J. Cancer 92, 389-395 (2005).

56. Nigg EA: origins and consequences of centrosome aberrations in human cancers. Int. J. Cancer 119, 2717-2723 (2006).

57. Ganem NJ, Godinho SA, Pellman D: A mechanism linking extra centrosomes to chromosomal instability. Nature 460, 278-282 (2009).

58. Kwon M, Godinho SA, Chandhok NS et al.: Mechanisms to suppress multipolar divisions in cancer cells with extra centrosomes. Genes Dev. 22, 2189-2203 (2008).

59. Thompson SL, Compton DA: Examining the link between chromosomal instability and aneuploidy in human cells. J. Cell Biol. 180, 665-672 (2008). 